\title{
The Effect of Metacognitive Strategy Use via Task Supported Language Teaching on Vocabulary Acquisition: The Case of Iranian EFL learners
}

\author{
Fatemeh Dehghan (Corresponding author) \\ M. A. student \\ Dept. of English, Science and Research Branch, Islamic Azad University, Tehran, Iran \\ Tel: 98-91-3273-6081Ｅ-mail: Fatemeh480@yahoo.com
}

Dr. Mohammad Khatib

Associate Professor, Allameh Tabataba'i University, Tehran, Iran

Tel: 98-91-2310-6816_E-mail: mkhatib27@yahoo.com

Received: July 10, 2015 Accepted: August 20, 2015 Published: August 27, 2015

doi:10.5296/ijele.v3i2.8206 URL: http://dx.doi.org/10.5296/ijele.v3i2.8206

\begin{abstract}
The main difference between proficient and less proficient learners lies in the conscious ability to the so-called metacognition. Students who possess good metacognition know how to learn and what to do in any learning circumstances. The purpose of this study was to investigate the effect of metacognitive strategy use via task supported language teaching on vocabulary acquisition. To achieve this aim, 40 learners studying at Shahid Sadoughi University of Medical Sciences were put into experimental and control groups. For the experimental group, 10 units of 'Barron's Essential Words for the TOEFL (IBT) were covered through 'metacognitive strategy use', 'vocabulary acquisition', and 'task supported language teaching' principles of vocabulary teaching. In the case of the control group, the lesson plan was covered in accordance with the cognitive strategies and based on the exercises posed in the book. A sample of vocabulary test was administered as the pretest and another parallel one for the post-test of the study after each group was exposed to the treatment for 10 sessions. Data analyses revealed that the experimental group outperformed the control group in the post-test; in this regard, the efficacy of the teaching protocol for experimental group is confirmed.
\end{abstract}

Keywords: Metacognition, Learning Strategies, Task supported Language Teaching 


\section{Introduction}

It has been claimed that successful language learners have their own special ways of using learning strategies. Stern and Rubin (1975) were probably among the first researchers who brought up the idea of successful language learners. The idea can probably help us with both understanding more about the nature of language learning and also facilitating the language learning processes for others.

Research into language learning strategies began in 1960s as a reaction to teacher-centered education. It appears that the greater emphasis on learners and learning resulted in changes mostly reflected in the amount of attention given to learning strategies. However, learning strategies have been used for thousands of years as Oxford (1990) mentioned that mnemonic or memory tools were used in ancient times to facilitate narrators remember their lines. Chamot (2004, p. 14) stated that "learning strategies are the conscious thoughts and actions that learners take in order to achieve a learning goal. Strategic learners have metacognitive knowledge about their own thinking and learning approaches, a good understanding of what a task entails, and an ability to orchestrate the strategies that best meet both the task demands and their own learning strengths".

$\mathrm{Gu}$ (1994) stated that specific strategies used by second language learners for the acquisition of new words in the second language are called "Vocabulary Learning Strategies", and VLS are considered as a part of language learning strategies. Several scholars have produced taxonomies of vocabulary learning strategies ( Gu \& Johnson, 1996; Schmitt, 1997; Nation, 2001), but among all, one of the most important figures is Schmitt (1997) who dedicated a chapter to vocabulary learning strategies. Many scholars shed some light in vocabulary acquisition under the principles of TBLT. Two of the most worthy-mentioned sources are Ellis (2003), and Hedge (2000). In these valuable sources, hot debates on vocabulary acquisition or learning by TBLT principles application are presented. A necessary distinction to make is between TBLT (task-based language teaching), and TSLT (task-supported language teaching. The former as Ellis (2003, p. 351) stated is kind of teaching "that is based entirely on tasks. Such teaching makes use of a procedural syllabus", but the latter is kind of teaching "that utilizes tasks to provide free practice in the use of a specific linguistic feature that has been previously presented and practiced.

Teaching of metacognitive skill is a valuable use of instructional time for a second language teacher. When learners reflect upon their learning strategies, they become better prepared to make conscious decisions about what they can do to improve their learning. Strong metacognitive skills empower second language learners (Anderson, 2002). O'Malley and Chamot (1990) stress the importance of metacognitive strategies when they state that "students without metacognitive approaches are essentially learners without direction or opportunity to plan their learning, monitor their progress, or review accomplishments and future learning direction" (p. 8).

So the main problem focused to be solved is addressing the appropriate use of metacognitive strategies in EFL contexts. Unfortunately, however, most of the teachers are fully or partially familiar with teaching innovative terms, they do not apply them in their classes. Due to the 
mentioned issue, most of the English classes do not possess the ample efficacy. The posed problem in the present study as is the conscious or subconscious ignorance use of metacognitive strategies in vocabulary acquisition. Considering the mentioned issues, this study aims to find out the effect of metacognitive strategy use on vocabulary acquisition via TSLT.

\section{Literature Review}

Research on language learning strategies, at first, attempted to identify useful strategies; subsequently, it developed frameworks for the categorization of these strategies.

Among myriad scholars, two are very noticeable, the first one is O'Malley and the second one is Oxford, O'Malley and Chamot et al. (1985) who presented a model of strategies. The model is divided into three major parts as: a) metacognitive strategies, b) cognitive strategies, and c) socio-affective strategies. Oxford (1990) posed a different model of strategies. She divided the strategies in two general groups as direct and indirect ones. Direct strategies consist of memory, cognition, and compensation categories; indirect ones, on the other hand, consist of metacognitive, affective, and social categories. According to O'Malley and Chamot (1990), cognitive and metacognitive strategies are often used together. Graham (1997) stated that the distinction between cognitive and metacognitive strategies is important, partly because they help us to indicate which strategies are the most important ones in determining the effectiveness of learning. Graham believes that metacognitive strategies that allow students to plan, control, and evaluate their learning, have the most central role to play in improvement of learning. Anderson (2002, p.1), believes that "developing metacognitive awareness may also lead to the development of stronger cognitive skills". Since metacognitive strategies are the focus of this study, just the sub-categorizations of them are used. In the process of identification of language learning strategies, Schmitt (1997) realized that many of these strategies deal with vocabulary learning

Cubukcu (2008) presented a study of the teacher trainees in an English department who had received instruction in metacognitive awareness for reading comprehension. Metacognition or 'thinking about thinking' involves the awareness and regulation of thinking processes. Metacognitive strategies are those strategies which require students to think about their own thinking as they engage in academic tasks. Within this study, students were taught metacognitive strategies for reading in a five-week program they have joined voluntarily. The students have used reading logs to reflect on their own thinking processes as they were engaged in reading tasks. The purpose of the study is to determine the effectiveness of systematic direct instruction of multiple metacognitive strategies designed to assist students in comprehending text. Specifically, the reading comprehension and vocabulary achievement of 130 third year university students has been investigated to determine whether instruction incorporating metacognitive strategies has led to an increase in the reading comprehension of expository texts.

Zhao (2009) in a probe attempted to tap the relationship between metacognitive strategy training and vocabulary learning of college students through a five-week training program. It aimed to answer the following question: Can metacognitive strategy training facilitate 
vocabulary learning of Chinese college students? Questionnaire as well as tests was used in the study. One hundred and thirty-four students participated in the study; one class of 68 which received both cognitive vocabulary training and metacognitive training comprised the experimental group; the other class of 66 students served as the control group and received only cognitive strategy training without metacognitive component. The metacognitive strategy training for vocabulary learning of these students proved to be effective.

Mizumoto (2009) through a study examined the effectiveness of explicit instruction of vocabulary learning strategies (VLSs) over a ten-week semester with a group of 146 female EFL learners from two Japanese universities. A vocabulary test and questionnaires on VSLs and motivation were administered at the beginning of the course. The learners were divided into two groups based on the vocabulary test results: an experimental group and a control group. Only the experimental group received explicit instruction on VLSs in combination with their regular language lessons. The same instruments were administered at the end of the course to examine the changes in both the questionnaire responses and test scores. Qualitative analyses were also conducted to explore the findings in detail. The results show that the experimental group outperformed the control group in the vocabulary test. It was also found that (a) strategy training was effective for both changing the repertoire of strategies used and improving their frequency of use, (b) the training increased the use of certain strategies more than it did for other strategies, and (c) different types of learners exhibited different responses to the strategy instruction. This study's findings contribute to a better understanding of strategy instruction in general and VLSs in particular.

Ahmadi, Nizam Ismail, and Abdullah (2012) conducted a study which suggested reciprocal teaching strategy as a main factor to improve students' vocabulary learning in a foreign language. The purpose was to investigate whether reciprocal teaching strategy improves students vocabulary learning or not. Reciprocal teaching consists of four basic reading strategies: predicting, questioning, clarifying, and summarizing. Cognitive and metacognitive strategies are the reciprocal teaching strategies used to enhance students' vocabulary learning. The lack of good vocabulary learning skills is a main obstacle in a foreign language. One solution to this problem of poor vocabulary skill is the explicit teaching of vocabulary learning strategy. Researcher is going to define the key words, explain the models of vocabulary process, follow reciprocal teaching strategies, discuss cognitive and metacognitive strategies and elaborate the related research on reciprocal teaching, and state relationship between reciprocal teaching and vocabulary learning.

Seddigh and Shokrpur (2012) did a study aimed to investigate the use of vocabulary learning strategies among medical students at Shiraz University of Medical Sciences (SUMS) in Iran as an EFL context. A questionnaire was administered to 120 medical students (53 males, 67 females) to identify; 1) the effective types of vocabulary learning strategies used by the learners and 2) the differences in vocabulary strategy use based on gender. The results revealed that guessing and dictionary strategies were the most frequently used VLS and social and study preference strategies were the least used ones. The results of ANOVA showed that there were statistically significant differences in the mean scores of the eight strategies. As to gender, the females utilized more VLS than males especially in the case of guessing and note-taking 
strategies; the statistical analysis indicated a significant difference between the students' gender and their choice of VLS.

Rahimy and Shams (2012) conducted a probe to investigate the effectiveness of vocabulary learning strategies on Iranian EFL learners' vocabulary test score. To achieve this aim, fifty Intermediate level students from Kish English Institute were randomly selected from among fifteen classes after administering the Oxford Placement Test (OPT). Then, an intermediate level vocabulary test of 20 questions based on their class textbook named Total English was given to them. A questionnaire of vocabulary learning strategies (VLSQ) was, then, distributed among students to find out how each learner learned new vocabulary and in what way. Finally, the whole data gathered from OPT; vocabulary test and VLSQ were analyzed through SPSS by applying Chi-square and descriptive analysis. The findings, showed a significant effect of vocabulary learning strategies on EFL learners' performance in a vocabulary test.

\section{Methodology}

The present study was designed to determine the effect of metacognitive strategy use on vocabulary acquisition via TSLT. Hence, in this section the design, participants, procedures, instruments, and statistical analyses of the study were discussed in detail to shed light on the methodology of the current study.

\subsection{Design}

This research was a kind of quasi-experimental-quantitative study. It was experimental because one independent variable was manipulated to determine its effect on another dependent variable in general, and it was quasi owing to the lack of random sampling involvement. The independent variable modified by the conductor was metacognitive strategy use. Although metacognitive strategies were considered as the main independent variable, there was another subcategory of independent variable, i.e., Task- supported language teaching (TSLT) in this study. Task- supported language teaching (TSLT) was the subcategory. Hence, one of the innovations of the present study was suggesting a triangulation of the two independent variables to investigate their combined effect on vocabulary acquisition.

\subsection{Participants}

The participants of the study were 40 upper-intermediate EFL learners studying Medicine at Shahid Sadoughi University of Medical Science, Yazd, selected according to the availability sampling. At first a Test of Cambridge University' was administered to a large number of participants and among whom 45 ones were upper-intermediate. Finally, 40 were called upon to take part in the main study. Their age average was 22 , and because of their age they had cooperation with each other, also their eagerness to learn was good. Also, their competition due to diversity of males and females was highly increased.

\subsection{Instruments}

In general, seven instruments were used in the present study. They are listed below:

\section{Longman Dictionary of Contemporary English:}


This dictionary was mainly used for adopting the examples as an authentic source to show the appropriate use of the new words in the context.

\section{Essential Words for the TOEFL:}

This book is one of the common available books dedicated to vocabulary learning. In addition to 30 comprehensive units which introduce 15 academic words, exercises such as: finding the meaning in context and finding a synonym in paragraphs are common. Also, there are some other chapters on different issues related to IBT, but only first 10 units of chapter 6 were covered.

\section{Matrix Word 2010:}

According to table 3.1 (Below), there are some matrixes in triangulation presentation. To write a diary, the participants are expected to type their accomplishments in MS Word 2010, so this factor is one of the important ones to divide the participants into experimental and control groups.

\section{Leitner Box:}

In accordance with table 3.1, the experimental participants were taught to use the mentioned instrument to transfer the new words from their working memory to the long-term memory and save it forever.

\section{Flash Cards:}

In using Leitner Box, considering time saving of flash cards making, the flash cards of the mentioned book available in the market was introduced to the participants.

\section{Jet Audio:}

To record their voices for the speaking tasks, participants are required to use this software. There are many other options, but considering its user-friendly style, it is highly preferred.

\subsection{Procedures}

To accomplish the purpose of the study, six steps were taken. These steps are as follows.

A considerable number of EFL volunteers claiming they were Upper-Intermediate were called upon to participate in Cambridge Placement Test. The test includes 20 questions for Listening, 20 questions for Reading Comprehension, 30 questions for Language Use (Grammar \& Vocabulary), Placement Essay, and, Placement Conversation. Based on the Placement Guidelines of the mentioned package, those who can get the average 9 out of 12 are considered as upper-intermediate participants (Lesley, Hansen, and Zukowski, 2005).

As a pre-test, a researcher-made vocabulary test including three sections was prepared. The sections were selected in accordance with the variety of exercises in Matthiesen (2011), namely 'matching', 'meaning identification in line(s)', and 'finding a synonym in the text'. The prepared test was distributed among them enjoying 30 questions and 25 minutes allotted time. 
The participants attended 10 sessions of treatment. And they were expected to have three sessions in a week. In these sessions, the first ten units of 'Barron's Essential Words for the TOEFL (IBT) were covered. A mandatory word of caution should be added. Owing to the nature of experimental and control groups, two teaching procedures were conducted. For the experimental group, the mentioned units were covered in accordance with the posed triangulation of three combined variables of the study, namely 'metacognitive strategy use', 'vocabulary acquisition', and 'TSLT' principles of vocabulary teaching. To mix the mentioned factors, the posed scenario is as follows:

Table 3.1. Variables triangulation

\begin{tabular}{|c|c|c|c|}
\hline Metacognitive Strategies & Focused Tasks & Vocabulary & $\begin{array}{r}\text { Acquisition } \\
\text { Strategy }\end{array}$ \\
\hline Monitoring & Diary & & Writing \\
\hline Planning & Leitner Box & & Flash Cards \\
\hline Evaluation & Recorded File & & Speaking \\
\hline
\end{tabular}

As mentioned, the preceding table was used as the lesson plan for the experimental group. In the case of the control group, considering the fairness issues, the mentioned sources were covered in treatment sessions, but the lesson plan was arranged just in accordance with the cognitive strategies and based on the exercises posed in the book.

After the treatment sessions, learners received a posttest. The arrangements of the questions were exactly like the pretest ones.

\subsection{Data Analysis}

Since there are two groups in the present study and we want to compare their vocabulary scores from the pretest to the posttest, a paired samples t-test was used. Also, to compare the posttest mean scores of the two groups, an independent samples t-test was run.

\section{Results and Discussion}

Research Question: Does metacognitive strategy use via task supported language teaching have any statistically significant effect on vocabulary acquisition?

Table 1. Descriptive Statistics of Control and Experimental Groups

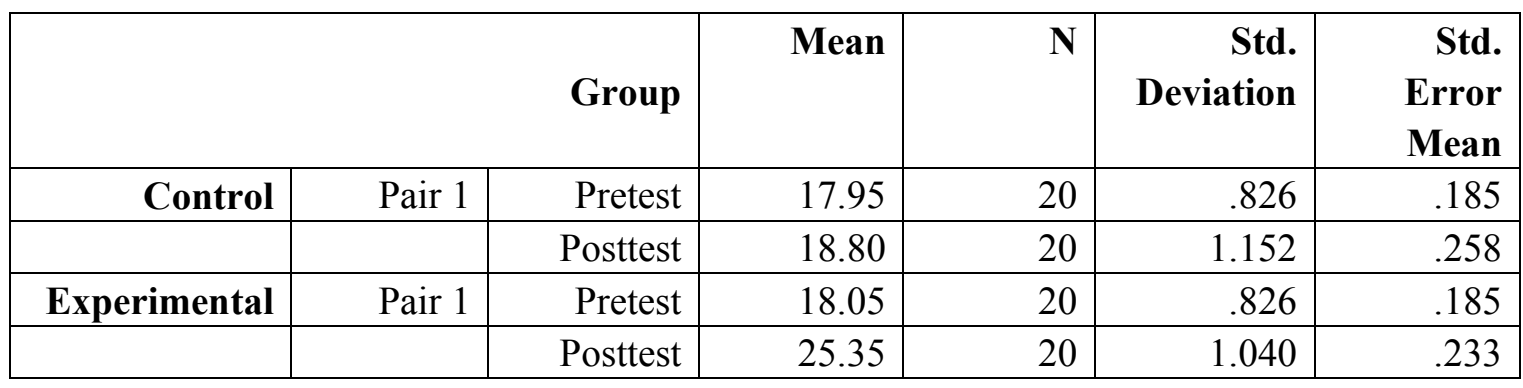


As Table 1 reveals, the vocabulary mean score of the control group has increased from the pretest $(\mathrm{M}=17.95, \mathrm{SD}=.82)$ to the posttest $(\mathrm{M}=18.80, \mathrm{SD}=1.15)$. Likewise, the Experimental group mean score has experienced a noticeable increase from the pretest $(\mathrm{M}=18.05, \mathrm{SD}=.82)$ to the posttest $(\mathrm{M}=25.32, \mathrm{SD}=1.04)$. to find out if the gains in the two groups from the pretest to the posttest have been statistically significant, two series of paired samples t-test were run as follows:

Table 2. Paired Samples t-tests for Both Control and Experimental Groups

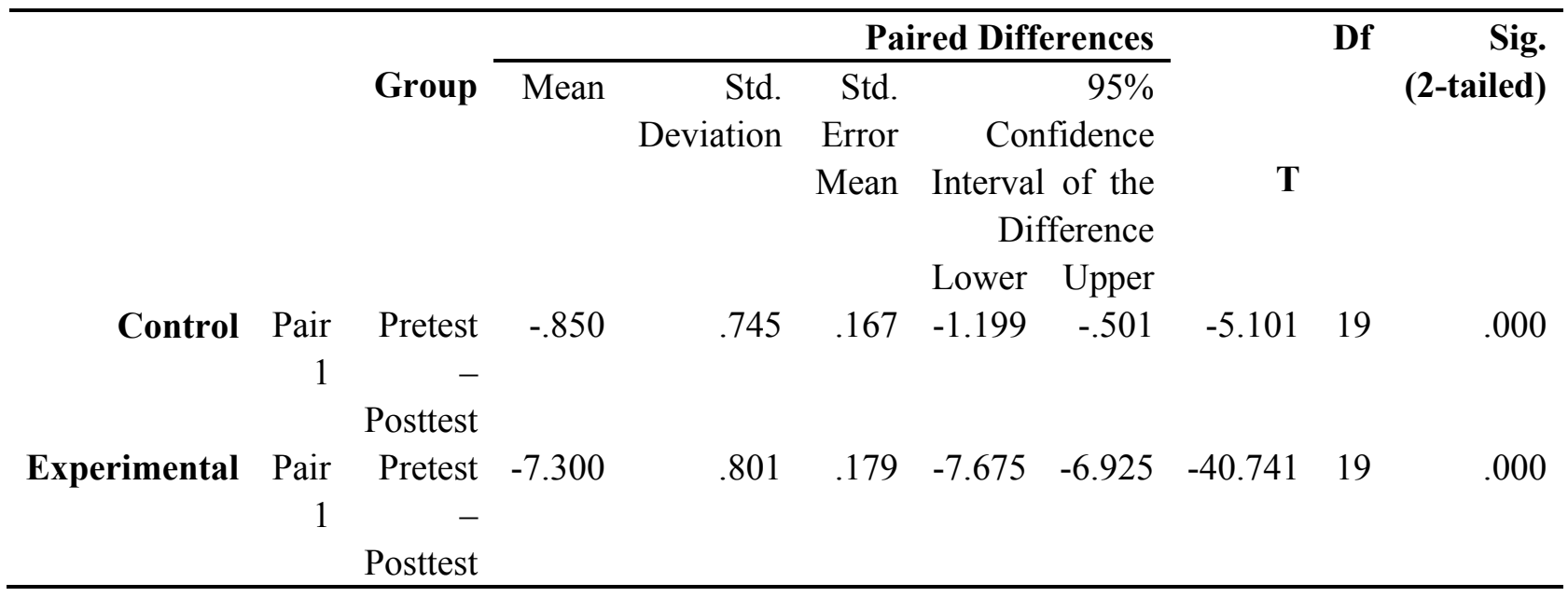

As shown in Table 2, two series of paired samples t-tests were applied to see if the difference between the control and experimental group vocabulary gains from the pretest to the posttest were statistically meaningful. The results indicated a statistically significant increase in the vocabulary gains from the pretest to the posttest since the sig value for both control and experimental groups $(p=.000, p=.002)$ is below 0.05 . Therefore, it is inferred that the gains were statistically significant.

Table 3. Descriptive Statistics of Posttest Mean Scores

\begin{tabular}{|l|l|l|l|l|l|}
\hline \multirow{2}{*}{ Group } & & & & Std. Error \\
\cline { 3 - 6 } Posttest & Control & 20 & 18.80 & 1.152 & .258 \\
\cline { 2 - 6 } & experimental 20 & 25.35 & 1.040 & .233 \\
\hline
\end{tabular}

As depicted in Table 3, the vocabulary means score of the experimental group on the posttest is 25.35 , however, the control group mean score of vocabulary on the posttest is 18.80 . 
Table 4. Independent samples t-test concerning the vocabulary posttest of control and experimental groups

\begin{tabular}{|c|c|c|c|c|c|c|c|c|c|}
\hline & \multicolumn{2}{|c|}{$\begin{array}{ll}\text { Levene's } & \text { Test for } \\
\text { Equality } & \text { of } \\
\text { Variances }\end{array}$} & \multicolumn{7}{|c|}{ t-test for Equality of Means } \\
\hline & \multirow[b]{2}{*}{$\mathrm{F}$} & \multirow[b]{2}{*}{ Sig. } & \multirow[b]{2}{*}{ t } & \multirow[b]{2}{*}{ df } & \multirow{2}{*}{$\begin{array}{l}\text { Sig. } \\
\text { (2-tailed }\end{array}$} & \multirow{2}{*}{$\begin{array}{l}\text { Mean } \\
\text { Differen } \\
\text { ce }\end{array}$} & \multirow{2}{*}{\begin{tabular}{|l} 
Std. \\
Error \\
Differen \\
ce
\end{tabular}} & \multicolumn{2}{|c|}{\begin{tabular}{|l|}
$95 \%$ Confidence \\
Interval of the \\
Difference
\end{tabular}} \\
\hline & & & & & & & & Lower & Upper \\
\hline \begin{tabular}{|ll} 
Postt & Equal \\
est & variances \\
assumed
\end{tabular} & .016 & .901 & $\begin{array}{l}-18.8 \\
77\end{array}$ & 38 & .000 & -6.550 & 347 & -7.252 & -5.848 \\
\hline $\begin{array}{ll}\text { Equal } & \\
\text { variances not } \\
\text { assumed }\end{array}$ & & & $\begin{array}{l}-18.8 \\
77\end{array}$ & $\begin{array}{l}37.61 \\
1\end{array}$ & .000 & -6.550 & 347 & -7.253 & -5.847 \\
\hline
\end{tabular}

As tables 4.7 indicates, an independent-samples t-test were run to discern if there was any discrepancy among control and experimental groups' mean score with regard to the vocabulary on the posttest. Hence, the analysis of data demonstrated there was a significant difference among the two means scores as the Sig value $(p=.000)$ it is below 0.05 . Hence, the results of this study show that although the mean score of the experimental and control group were similar on the pretest, the experimental group receiving metacognitive strategy use via task supported language teaching outperformed the control group on the posttest. The results of the current study confirm Cubukcu's (2008) research showing that the experimental group achieved significantly better results than the control group. Also, this study affirms Zaho (2009) results. He showed that the experimental group outperformed the control group in the post-training vocabulary test and the questionnaire displayed in what aspects the students improved these metacognitive strategies. Also results are in line with Rahimy and Shams (2012). Their findings revealed a significant effect of vocabulary learning strategies on EFL learners' performance in a vocabulary test.

\section{Conclusion}

One major aim pursued in this inquiry was to recognize the effect of metacognitive strategy use via task supported language teaching on vocabulary acquisition. The findings show the post-test means of two groups are not the same, that is, 18.80 for the control group, and 25.35 for the experimental group. As the pretest mean scores were adjacent, therefore, the designed scenario for the experimental group caused a statistically significant difference. 


\subsection{Pedagogical Implications}

The findings of the present study can be used in teaching especially in the realm of vocabulary acquisition. Since one of the common questions of the EFL learners is dedicated to the appropriate way to memorize vocabulary acquisition, designing some methods to teach the new vocabulary can be a fruitful alternative. Most of learners think that the only way to master the words particularly the academic ones is just memorization, but as many scholars such as Richards (1976), Allen (1983), Nation (1990), Schmitt (1997), Matthiesen (2011), and Zhang and $\mathrm{Li}$ (2011) mention vocabularies cannot be learned only by memorization. There are many factors that if they are not controlled, they can play as intervening variables in this progress.

1. Transfer of the new words from short- term memory to long term(Ausubel,1963),

2. Subsumption of the new words (Anderson and Ausubel, 1965),

3. Linking the new ones with the previous ones (Ausubel, 1963),

4. Role of context (Yule, 1996)

5. Role of vocabulary force, it means the positive, negative, and the neutral ones (Cowie, 2009),

6. Collocations (Cowie, 2009),

7. Concordances (Cowie, 2009),

and many other related factors which should be controlled for a better learning. To learn a new vocabulary in any language does not mean to memorize the first meaning of that word in L1 for example the first word of 504 absolute words is "abandon", many learners memorize this word as "Tark kardan" and go through the next one, but after some hours, days, weeks, months unfortunately forgetting would happen. Even if he does not forget the Persian equivalent, he is not able to understand the meaning of the word in an unfamiliar context or make some native -like sentences by the use of that word. This is not the end of the story, denotations and connotations are important as well. Many words when they put in different contexts have different meanings or academically speaking, different semantic behaviors.

\subsection{Suggestions for further Studies}

There are some suggestions to conduct further studies:

\section{To utilize other models for metacognitive strategies such as Oxford Model}

In this regard, because the oxford model is much more comprehensive in comparison with the posed model in the present study, probably the variety in designing a researcher-made lesson plan would be more accessible.

\section{To examine other protocols to teach vocabularies}

As considered, the applied scenario in the present study was perfectly useful. Other researcher-made scenarios can be utilized to obtain possibly the same or different conclusions. A good research should be replicable; therefore, different scenarios with the same findings can 
boost the idea behind this probe conduction that vocabulary acquisition is not just a self- study activity.

\section{To design some scenarios to teach other skills or sub-skills}

In this study, since the focus was on vocabulary acquisition, the designed scenario concentrated on vocabulary acquisition; while, some other treatment programs for other skills and sub skills can be tested to be constructive in the EFL context. An innovative and critical teacher tries to do best in his classroom since he believes the rudiments of any class are different from the others and by a remedy all the infections cannot be cured.

\section{To teach vocabularies in the form of some independent or integrated tasks}

Another recommended task would be the teaching vocabulary in the form of some independent and integrated tasks. A simple example can reveal the fact behind. In PBT version of the TOEFL, in some cases, some vocabulary questions were posed such as:

- Mr. Jackson is considered a man of moderate views.

a. Modern

b. Stern

c. Reasonable

d. predictable (Ketabi, 2006)

but with the advent of iBT version, this type of question was extinct. Instead, when a vocabulary is wanted to check, it would be checked in a context, it means in a passage. Grammar and vocabulary are two fundamental cornerstones in learning any language; therefore, designing some integrated tasks to boost them can lead to their improvements.

5. To raise the pragmatic and discoursal awareness of the EFL learners in the case of the academic vocabularies

As stated, to learn a new vocabulary, memorizing the L1 equivalent is not a good way; however, it is suggested by some frauds to make money out of language teaching. Vocabulary must be internalized in a context; it must be subsumed for further retrieval. Regarding, raising the pragmatic and discoursal awareness is to be very important. For example, there are some words that they can be called as synonyms. However, in most of the cases, the synonymous words do not overlap each other perfectly, and at least in one semantic feature, they are different. Pragmatic and discoursal awareness can solve the posed problem. For example:

- I love my job so much.

- $\quad$ I love my job too much.

The use of different intensifiers can lead to two different meanings. Although "so" and "too" can be synonymous and interestingly in Persian both of them can be translated as "Kheili", but syntax-pragmatic interface shows a different reality. 
6. To conduct a study and compare more than two groups

Statistically speaking, in parametric realm of analyses, there are two major classifications. Group means can be compared as some examples were revealed in the present study in the form of different types of $\mathrm{T}$ Tests, or the group relationships as Pearson correlation showed some of them. Some comparisons mostly focused on two groups, namely experimental and control, but in more advanced analyses, the number of the groups can be added or some other independent or dependent variables can be added to study to conduct some much more advanced analyses such as ANCOVA or MANCOVA to compare the means between and within groups.

7. To add some other variables such as age, sex, and nationality for the conduction of multivariate analyses

As mentioned, by adding some other independent, dependent, or moderate variables, the way would be paved to conduct some multivariate analyses to compare the means between and within groups and show some more fascinating results.

\section{References}

Allen,V.(1983). Techniques in teaching vocabulary. Oford: OUP.

Anderson. R., \& Ausubel, D. (Eds.). (1965). Reading in the psychology of cognition. New York: Holt, Rinehart \& Winston.Ausubel, D. (1963). Cognitive structure and the facilitation of meaningful verbal learning. Journal of Teacher Education, 14, 217-221.

Allen,V.(1983). Techniques in teaching vocabulary. Oxford: OUP.

Ahmadi, M.R., Ismail, H. N. \& Abdullah, M. K. (2012). Improving vocabulary learning in foreign language learning through reciprocal teaching strategy. International Journal of Learning \& Development, 2(6), 186-210.

Anderson, N. J. (2001a). The role of metacognition in second language teaching and learning. ERIC Digest, 3-4.

Chamot, A. (2004). Issues in language learning strategy research and teaching. Electronic Journal of Foreign Language Teaching, 1(1), 14-26. Retrieve from http://e-flt.nus. edu.sg./

Chamot, A. U., \& O'Malley, J. M. (1985). A cognitive academic language learning approach: An ESL content-based curriculum.

Chamot, A. U., \& O'malley, J. M. (1987). The cognitive academic language learning approach: A bridge to the mainstream. TESOL quarterly, 21(2), 227-249.

Cubukcu, F. (2008). Enhancing vocabulary development and reading comprehension through metacognitive strategies. Issues in Educational Research, 18 (1).strategy research. New York: Springer Verlag.Cowie, A.P. (2009). Semantics. Oxford: OUP.

Ellis, R. (1997). SLA Research and Language Teaching. Oxford University Press, 198 Madison Avenue, New York, NY 10016-4314. 
Ellis, R. (2003). Task-based language learning and teaching. Oxford: OUP.

Graham, S. (1997). Effective language learning: positive strategies for advanced level language learning. Clevedon: Multilingual Matters.

Gu, P. Y. (1994). Vocabulary learning strategies of good and poor Chinese EFL Learners. The twenty-eight annual conventional and exposition, P. 27 Baltimore.

Gu, Y., \& Johnson, R.K. (1996). Vocabulary learning strategies and language learning outcomes. Language learning. 46(6), 643-679. Retrieved from http://dx.doi.org/10.1111/J.16/67-1770.1990

Kondo, S. (2004). Raising pragmatic awareness in the EFL context. Sophia Junior College Faculty Bulletin, 24, 4972.

Lesley, T., Hansen, Ch. \& Zukowski, J. (2005). Interchange $\left(3^{r d}\right.$. ed.)/Passages, Placement and Evaluation Package. Cambridge: Cambridge University Press.

Ketabi, S. (2005). Developing vocabulary for TOEFL. Isfahan: Mani Publications.

Lesley, T., Hansen, Ch. \& Zukowski, J. (2005). Interchange $\left(3^{\text {rd }}\right.$. ed.)/ Passages, Placement and Evaluation Package. Cambridge: Cambridge University Press.

Matthiesen, S. (2011). Essential words for the TOEFL (iBT). UK: Longman.

Mizumoto, A. (2009). Examining the effectiveness of explicit instruction of vocabulary learning strategy with Japanese EFL university students. Language Teaching Research, 13 (4), 1-44. Retrieved from http:// itrsagepub. com/ content/ 13/4/425.Linguistics, Allameh Tabatabaie University, Tehran, Iran.Nation, P. (1990).Teaching and learning vocabulary. New York: Newbury House.

Nation, P. (1990). Teaching and learning vocabulary. New York: Newbury House.

Nation, I. S. P. (2001). Learning vocabulary in another language. Cambridge University Press.

Nunan, D. (1989). Designing tasks for the communicative classroom. Cambridge University Press.

O ' Malley, M., \& Chamot, A. (1990). Learning strategies in second language acquisition. New York: Cambridge University Press.

O'malley, J. M., \& Chamot, A. U. (1990). Learning strategies in second language acquisition. Cambridge University Press.

O’Malley, J. M., Russo, R. P., Chamot, A. U., \& Stewner-Manzanares, G. (1988). Applications of learning strategies by students learning English as a second language. Learning and study strategies: Issues in assessment instruction and evaluation, 215-31.

Oxford, R. (1990). Language Learning strategies: What every teachers should know. New York: New bury House. 
Rahimi, R., \& Shams, K. (2012). An investigation of the effectiveness of vocabulary learning strategies on Iranian EFL learners' vocabulary test score. International Education Studies, 5(5) 141-152. http://dx.doi.org/10. 5539/ ies. v5n5p141

Richards, J. C. (1976). The role of vocabulary teaching. TESOL Quarterly, 10(1), 77-89.

Richards, J. C., \& Schmidt, R. W. (2013). Longman dictionary of language teaching and applied linguistics. Routledge.

Rubin, J. (1975). What the "good language learner" can teach us. TESOL Quarterly, 9, 41-51.

Schmitt, N. (1997). Vocabulary learning strategies. In N. Schmitt, \& M. McCarthy (Eds.), vocabulary: description, acquisition and pedagogy.

Stern, H. H. (1975). What can we learn from the good language learner? Canadian Modern language Review, 34, 304-318.

Yule, G. (1996). Pragmatics. Oxford: Oxford University Press.

Zhang, B., \& Li, Ch. (2011). Classification of L2 vocabulary learning strategy: evidence from exploratory and confirmatory factor analysis. RELC Journal, 42, 141-154. Retrieved from Htpp://rel.sagepub.com/

Zhao, N. (2009). Metacognitive strategy training and vocabulary learning of Chinese college students. English Language Teaching, 2(4), p123.

\section{Copyright Disclaimer}

Copyright for this article is retained by the author(s), with first publication rights granted to the journal.

This is an open-access article distributed under the terms and conditions of the Creative Commons Attribution license (http://creativecommons.org/licenses/by/3.0/). 